Review Article

\title{
Desarda repair versus other inguinal hernia repairs: a review of global data of 35578 patients
}

\author{
Mohan P. Desarda* \\ Department of Hernia Surgery, Indian Hernia Institute, Pune, Maharashtra, India \\ Received: 11 December 2021 \\ Revised: 15 January 2022 \\ Accepted: 17 January 2022

\section{*Correspondence:} \\ Dr. Mohan P. Desarda, \\ E-mail: desarda@desarda.com
}

Copyright: () the author(s), publisher and licensee Medip Academy. This is an open-access article distributed under the terms of the Creative Commons Attribution Non-Commercial License, which permits unrestricted non-commercial use, distribution, and reproduction in any medium, provided the original work is properly cited.

\begin{abstract}
The aim of the present review study was to compare the outcomes of non-mesh Desarda technique with open mesh, Bassini and Lap repairs for inguinal hernia over a period of last 20 years. An internet search for RCTs/comparative studies comparing outcomes between Desarda and other repairs like open mesh, Bassini and Lap repairs were done. Search for individual studies was also conducted. RCT/comparative studies and individual non comparative studies comprising 35578 patients were found in search. All those published articles were downloaded from the internet. Some articles were directly obtained from the authors. Outcomes of these articles were evaluated and compared for recurrence, chronic pain, complications, free mobility, return to normal work and cost. A total number of 80 RCTs/comparative studies and 53 individual studies were included in this review with total number of 35578 patients. Recurrence $0.87 \%$ versus $5.6 \%$, chronic pain $1.8 \%$ versus $22.5 \%$, complications $6.87 \%$ versus $20.6 \%$, free mobility 37.6 hours versus 77.2 hours, return to normal work 10.2 days versus 16.7 days and cost $\$ 40.8$ versus $\$ 68.5$ was seen in Desarda versus other repairs, respectively. Desarda repair showed much superior results over other repairs like open mesh, Bassini or Lap repairs in terms of recurrence, chronic pain, complications, free mobility, return to normal work and the cost.
\end{abstract}

Keywords: Desarda, Bassini, Mesh, LAP, Inguinal hernias, Repairs, Review

\section{INTRODUCTION}

The author postulated that a physiologically dynamic protection gave much better results after hernia repair than static protection given by mesh. ${ }^{1,2}$ The author accordingly had developed and published no mesh operation techniques on physiological principle for inguinal hernia in 2001. ${ }^{3}$ Mesh repairs, either open or laparoscopic were associated with foreign body complications. ${ }^{4-6}$ So, it will be useful for the readers to see this review and to evaluate the outcomes in this study comparing no mesh Desarda repair with other repairs over last 20 years. This study was done to collect the global data on Desarda repair versus other repairs for inguinal hernias published from 2001 to 2021 and analyse its results.

\section{METHODS}

A literature search was conducted using electronic databases, PubMed (including MEDLINE), Google scholar, EMBASE, Research gate, Cochrane library data base. The main search words used were Desarda repair, Desarda vs Bassini, Desarda vs Shouldice, Desarda vs Lichtenstein, Desarda vs mesh, Desarda vs laparoscopic repairs and Desarda technique. Individual doctors were contacted, wherever possible, who were operating by Desarda technique and received data of their published or unpublished data from them. Such search for the 
published research articles was continued on the internet for a period of one-year in 1920-21. 80 RCTs and comparative studies and 53 individual studies done by different authors from 2001-2021 were found and downloaded from the internet and some articles were received from the authors.

The data collected from these articles was tabulated in an excel sheet for comparison and drawing the percentage averages of the different parameters under study in this review. Recurrence, chronic groin pain, complication rates, free mobility, cost and time to return to normal activities were important six parameters on which any type of inguinal hernia repair technique was evaluated to consider its efficacy and credibility. The values of these parameters were extracted from the original studies and entered in to excel sheet for further analysis. Values extracted were converted to percentage points for recurrence, chronic groin pain and the complication rates for drawing the average values. Values extracted for free mobility were in hours, for return to normal activities in days and cost in dollars. Only those studies were considered for drawing averages where any one of the above parameters was included in that study. Only those studies were taken into consideration for the parameter of recurrences for drawing averages where this parameter of recurrences was taken into consideration. Similar format was applied for other parameters also so that the averages drawn for that parameter was accurate and did not get falsified by inclusion of other studies where that parameter was not considered. Thus, any study showing 0 value of any parameter was excluded while calculating the average percentage value of that parameter. This review study was significant because the follow up period in all those published articles ranged between 1 to 15 years.

PRISMA statement/flow chart for how studies were included/excluded could not be applied for this study due to diversity of the studies and due to different parameters considered in this study were not considered by every research article considered for this study.

\section{RESULTS}

80 RCTs and comparative studies comprising 19658 patients were included. 9580 patients were operated by Desarda technique and compared with 10078 patients operated by open mesh (72 studies), Bassini (5 studies) and Lap (TEP 1, TAPP 2). The data for this was analysed (Table 1).

53 individual studies done by different authors comprising 6347 patients were also included in this study and the data was analysed (Table 2).

Data of 9573 patients operated by different surgeons but not published in any journal was collected. Part of this data was already presented in the first world hernia conference held in 2015 at Milan, Italy. This data was also analysed (Table 2).

Thus, the total data of 35578 patients was collected. It included 25500 patients operated by Desarda technique and 10078 patients operated by mesh or non-mesh technique (Bassini, open mesh and Lap repairs). The results shown by Desarda technique and other techniques were analysed and shown in percentages for recurrence rate, chronic groin pain, complication rate and free mobility in hours and return to normal activities in days (Table 3). The summary of the results was as follows.

\section{Recurrence rate}

The recurrence seen in Desarda repair was $0.87 \%$ as against the $5.6 \%$ seen in other repairs. This difference was significant.

\section{Chronic groin pain rate}

The chronic groin pain rate seen in Desarda repair was $1.8 \%$ as against the $22.5 \%$. This difference was significant.

\section{Complication rate}

The complication rate seen in Desarda repair was $6.87 \%$ as against the $20.6 \%$. This difference was significant.

\section{Free mobility}

The free mobility after operation was seen in 37.6 hours in Desarda repair whereas it was 77.2 hours in other operations. This difference was significant.

\section{Return to normal activities}

The patients on an average returned to normal nonstrenuous activities in 10.25 days in Desarda repair as against the 16.7 days in other operations. This difference was significant.

\section{Cost}

The cost involved was $\$ 40.8$ in Desarda repair as against the $\$ 68.5$ in other operations. This difference was significant.

\section{SYSTEMATIC REVIEW AND META-ANALYSIS STUDIES PUBLISHED BY 7 OTHER SURGEONS}

7 surgeons reviewed RCTs published by different surgeons comparing Desarda repair with other repairs in 16085 patients. 8034 patients operated by Desarda technique were compared with 8051 patients operated by other techniques (Table 4). 
Table 1: 80 RCT/comparative studies on 19658 patients; Desarda versus mesh-72; Desarda versus Bassini-5; Desarda versus TEP-1, TAPP-2.

\begin{tabular}{|llll|}
\hline Parameters & Desarda & Mesh and others & Total patients/remarks \\
\hline Number of patients & 9580 & 10078 & 19658 \\
\hline Recurrence (\%) & 1.10 & 5.60 & Significant diff. \\
\hline Chronic groin pain (\%) & 3.50 & 22.50 & Significant diff. \\
\hline Complications (\%) & 9.50 & 20.60 & Significant diff. \\
\hline Free mobility (hours) & 50.6 & 77.2 & Significant diff. \\
\hline Return to normal work (days) & 11.3 & 16.7 & Significant diff. \\
\hline Cost (\$) & 40.8 & 68.5 & Significant diff. \\
\hline
\end{tabular}

Table 2: 53 published individual studies of 6347 pts+unpublished data of 9573 pts=15920 patients.

\begin{tabular}{|llll|}
\hline Parameters & Published & Unpublished & Total/average \\
\hline Number of patients & 6347 & 9573 & 15920 \\
\hline Recurrence (\%) & 1.10 & 0.20 & 0.65 \\
\hline Chronic groin pain (\%) & 0.20 & 0 & 0.10 \\
\hline Complications (\%) & 6.70 & 1.80 & 4.25 \\
\hline Free mobility (hours) & 31.2 & 18 & 24.6 \\
\hline Return to normal work (days) & 11 & 8 & 9.5 \\
\hline
\end{tabular}

*(unpublished data: Robert Tomas 3500+Desarda 2300+others 3773: as per data from website www.ufirsthealth.com and as per data presented in the World hernia conference 2015).

Table 3: Combined averages of total Desarda versus total other repairs.

\begin{tabular}{|llll|}
\hline Parameters & Desarda & Other repairs & Total/average \\
\hline Number of patients & 25500 & 10078 & 35578 \\
\hline Recurrence (\%) & 0.87 & 5.60 & Significant diff. \\
\hline Chronic groin pain (\%) & 1.80 & 22.50 & Significant diff. \\
\hline Complications (\%) & 6.87 & 20.60 & Significant diff. \\
\hline Free mobility (hours) & 37.6 & 77.2 & Significant diff. \\
\hline Return to normal work (days) & 10.25 & 16.7 & Significant diff. \\
\hline Cost $(\mathbf{\$})$ & 40.8 & 68.5 & Significant diff. \\
\hline
\end{tabular}

Table 4: Published systematic review articles by 7 surgeons.

\begin{tabular}{|llllll|}
\hline Authors & Year & Desarda & Mesh & Total & Remarks \\
\hline Emile $^{\mathbf{7}}$ & 2017 & 1079 & 1080 & 2159 & Significant diff. \\
\hline Lockhart $^{\mathbf{8}}$ & 2015 & 3183 & 3110 & 6293 & Significant diff. \\
\hline Ren $^{9}$ & 2016 & 226 & 226 & 452 & Significant diff. \\
\hline Bracale $^{\mathbf{1 0}}$ & 2019 & 1395 & 1396 & 2791 & Significant diff. \\
\hline Ahmed $^{\mathbf{1 1}}$ & 2020 & 1551 & 1626 & 3177 & Significant diff. \\
\hline Ge $^{\mathbf{1 2}}$ & 2018 & 500 & 514 & 1014 & Significant diff. \\
\hline Ndong & 2020 & 100 & 99 & 199 & Significant diff. \\
\hline Total patients & & 8034 & 8051 & 16085 & \\
\hline
\end{tabular}

Emile concluded that both Desarda and Lichtenstein provided satisfactory treatment for primary inguinal hernia. ${ }^{7}$ Recurrence rates and rates of complications were significantly less after Desarda repair.

Lockhart concluded that mesh and non-mesh repairs are effective surgical approaches in treating hernias, each demonstrating benefits in different areas. ${ }^{8}$
Ren concluded that the outcomes of primary inguinal hernia repair with Desarda and Lichtenstein methods were comparable. ${ }^{9}$ Desarda method had advantage in operating time, cost and recovery.

Bracale concluded that Desarda's hernia repair can be a valuable alternative to Shouldice technique for the treatment of primary inguinal hernia repair if a non-mesh 
technique was chosen, because of its reproducibility and quicker post-operative recovery. ${ }^{10}$

Ahmed concluded that Desarda and Lichtenstein were found to have comparable results in terms of recurrence rate, haematoma formation, testicular atrophy and time to return to normal daily activity. ${ }^{11}$ Desarda technique was superior to Lichtenstein in terms of reducing postoperative mesh-attributed complications such as SSI and seroma formation.

Ge concluded that the current evidence suggested that there was no difference between Desarda and Lichtenstein technique. $^{12}$

Ndong concluded that Desarda repair was good in emergency repair for inguinal hernias with superior results as compared with the mesh repairs. ${ }^{13}$

\section{DISCUSSION}

All abdominal organs were naturally protected against external or internal blows by the physiologically dynamic contraction of the muscles of the abdominal wall. Therefore, any abdominal wall hernia should also be repaired in such a way that this physiologically dynamic protection given by the muscles was restored to give the best possible results. The author accordingly had developed and published operation techniques on physiological principle for inguinal hernia and for midline abdominal wall hernias that yielded excellent results. ${ }^{14}$ This covered $95-99 \%$ abdominal wall hernias that now can be treated with author's technique without any foreign body implant thus avoiding foreign body complications seen with mesh repairs.

The author postulated that a physiologically dynamic protection gave much better results after hernia repair than static protection given by mesh. Tissue repairs like Bassini, Shouldice or MacVay repairs gave such physiological protection. But still these repairs could not become popular due to tension on sutures even at rest and complicated and complex inguinal floor excision as advised by the original authors as its first step. ${ }^{15-17}$ Later the general surgeons conveniently omitted this first crucial step and modified the operation as they wish. ${ }^{18,19}$ Naturally, the results in their hands were extremely poor as compared to the results seen with the original authors. Similarly, if the internal oblique muscle was weak then using such weak muscle for repair was bound to give higher failure rates. ${ }^{20,21}$ Internal oblique muscle may get weakened due to the aging process or as per the collagen theory. ${ }^{22}$ But the aponeurosis of the external oblique muscle was least affected by the aging process or the defect in collagen synthesis. Author uses strip of such strong and physiologically dynamic strip of the external oblique muscle. Additional strength given by the external oblique muscle to the weakened internal oblique muscle kept the strip strong and physiologically dynamic to give the lifelong protection against the recurrences.
Mesh implants did not give such physiologically dynamic protection, so the patient was not fully protected for couple of years till strong fibrous curtain was formed on the scaffold of the mesh. ${ }^{23-25}$ Mesh was associated with its own complications, it being a foreign body. ${ }^{26-28}$ Chronic groin pain had crippled many patients operated with mesh. ${ }^{29-31}$ Collagen theory was also not in favour of mesh repairs as was stated otherwise. Success of the mesh repair depended on laying down of fibrous tissue. And this process of laying down of the fibrous tissue itself was affected when there was defective collagen synthesis. Mesh also caused permanent damage of the muscles on which it was spread and sutured. So, it ended with once a mesh repair then always was a mesh repair. Mesh repair was rejected by the general surgeons when it was first introduced. But later Amid made it popular with aggressive marketing by the mesh manufacturing companies. $^{32}$ But now many people were going against the mesh repairs due to its many long lasting reported complications. ${ }^{33,34}$

On this background, this was the time to review whether tissue repairs were again finding a favour amongst many general surgeons and the population of the hernia patients. Therefore, it became crucial to see where the mesh repair, old traditional tension repairs or latest tension free, mesh free Desarda repair stood in terms of its efficacy and credibility. This review study was done by the author exactly to find this out by collecting total 133 articles published by different authors from 2001 to 2021 and analyse their outcomes. It was seen that Desarda repair showed much less recurrence rates, complication rates and chronic groin pain as compared to other repairs. Patients were freely mobile and returned to normal activities much faster and better as compared to other repairs. And it was also cheaper in cost as compared to mesh repairs. Systematic review and metaanalysis studies done by 7 other surgeons as referred in this article have also endorsed on the similar view.

\section{CONCLUSION}

Both Desarda and Lichtenstein technique provided satisfactory treatment for primary inguinal hernia. But the recurrence and complication rates were significantly less in Desarda repair with added advantage of no foreign body and reduced cost. Many large and small RCTs, comparative studies, individual studies and systematic review studies with follow up study of 1-15 years are reviewed in this article and it has equivocally endorsed that the Desarda technique is much superior to other repairs in terms of recurrences and complications. There is hardly any incidence of chronic groin pain and other complications specifically seen with mesh implants. Therefore, Desarda repair has a potential to be considered as the first line of treatment in the inguinal hernia repairs.

Funding: No funding sources

Conflict of interest: None declared

Ethical approval: Not required 


\section{REFERENCES}

1. Desarda MP. Surgical physiology of inguinal hernia repair-a study of 200 cases. BMC Surg. 2003;3:2.

2. Desarda MP. Concepts that prevent inguinal hernia formation-revisited. New concepts of inguinal hernia prevention. Ann Emerg Surg. 2017;2(1):1007.

3. Desarda MP. New method of inguinal hernia repair: A new solution. ANZ J Surg. 2001;71(4):241-4.

4. Amid PK, Lichtenstein IL. Lichtenstein open tension free hernioplasty. In: Maddern GJ, Hiatt JR, Philips EH, eds. Hernia Repair (Open vs Laparoscopic Approaches). Edinburgh: Churchill Livingstone; 1997; 117-22.

5. Taylor SG, O’Dywer PJ. Chronic groin sepsis following tension free inguinal hernioplasty. $\mathrm{Br} \mathrm{J}$ Surg. 1999;86(4):562-5.

6. Fawole AS, Chaparala RPC, Ambrose NS. Fate of the inguinal hernia following removal of infected prosthetic mesh. Hernia. 2006;10(1):58-61.

7. Emile SH, Elfeki H. Desarda's technique versus Lichtenstein technique for the treatment of primary inguinal hernia: a systematic review and metaanalysis of randomized controlled trials. Hernia. 2018;22(3):385-95.

8. Lockhart K, Dunn D, Teo S, Ng JY, Dhillon M, Teo $\mathrm{E}$, et al. Mesh versus non-mesh for inguinal and femoral hernia repair. Cochrane Database Syst Rev. 2018;9(9):011517.

9. Ren F. Non-mesh (Desarda) versus mesh (Lichtenstein) methods for inguinal hernia repair Meta-analysis and system review, 2016. China: Congress of the Asia Pacific Hernia Society; 2016.

10. Bracale U, Melillo P, Piaggio D, Pecchia L, Cuccurullo D, Milone M, et al. Is Shouldice the best non-mesh inguinal hernia repair technique? A systematic review and network metanalysis of randomized controlled trials comparing Shouldice and Desarda. Int J Surg. 2019;62:12-21.

11. Mohamedahmed AYY, Ahmad H, Abdelmabod AAN, Sillah AK. Non-mesh Desarda technique versus standard mesh-based lichtenstein technique for inguinal hernia repair: a systematic review and meta-analysis. World J Surg. 2020;44(10):3312-21.

12. Ge H, Liang $\mathrm{C}, \mathrm{Xu} \mathrm{Y}$, Ren $\mathrm{S}, \mathrm{Wu}$ J. Desarda versus Lichtenstein technique for the treatment of primary inguinal hernia: a systematic review. Int J Surg. 2018;50:22-7.

13. Ndong A, Tendeng JN, Diallo AC, Diao ML, Diop $\mathrm{S}$, Dia DA, et al. Is Desarda technique suitable to emergency inguinal hernia surgery? A systematic review and meta-analysis. Ann Med Surg. 2020;60:664-8.

14. Desarda MP. Small/medium size midline ventral hernias: 4-layer suture repair on physiological principle. IOSR-JDMS. 2020;19(6):1-9.

15. Brown RK, Galleti G, Tumm KS. New technique for the cure of inguinal hernia: by Edoardo Bassini in 1887 to 1890 . J Hist Med Allied Sci. 1966;21(7):401-7.

16. Vrijland WW, Tol MP, Luijendijk RW, Hop WCJ, Busschbach JJV, Lange DCDD, et al. Randomized clinical trial of non-mesh versus mesh repair of primary inguinal hernia. $\mathrm{Br} \mathrm{J}$ Surg. 2002;89(3):293-7.

17. Liem MS, Graaf Y, Steensel CJ, Boelhouwer RU, Clevers GJ, Meijer WS, et al. Comparison of conventional anterior surgery and laparoscopic surgery for inguinal hernia repair. $\mathrm{N}$ Engl J Med. 1997;336(22):1541-7.

18. Desarda MP. Physiological repair of inguinal hernia: a new technique (a study of 860 patients). Hernia. 2006;10(2):143-6.

19. Gilbert AI. Suture less repair of inguinal hernia. Am J Surgery. 1992;163(3):331-5.

20. Desarda MP. Inguinal herniorrhaphy with an undetached strip of external oblique aponeurosis: a new approach used in 400 patients. Eur J Surg. 2001;167(6):443-8.

21. Kux M, Fuchsjager N, Schemper M. Shouldice is superior to Bassini inguinal herniorrhaphy. Am J Surg. 1994;168(1):15-8.

22. Read RC. A review: the role of protease-anti protease imbalance I the pathogenesis of herniation and abdominal aortic aneurism in certain smokers. Post Grad Gen Surg. 1992;4(12):161-5.

23. Nienhuijs SW, Oort I, Keemers-Gels ME, Strobbe LJA, Rosman C. Randomized clinical trial comparing PHS, mesh plug repair and Lichtenstein repair for open inguinal hernia repair. Br J Surg. 2005;92(1):33-8.

24. Colak T, Akca T, Kanik A, Aydin S. Randomized clinical trial comparing laparoscopic totally extra peritoneal approach with open mesh repair in inguinal hernia. Surg Laparosc Endosc Percutan Tech. 2003;13(3):1915.

25. Neumayer L, Giobbie-Hurder A, Jonasson O, Fitzgibbons R, Dunlop D, Gibbs J, et al. Open mesh versus laparoscopic mesh repair of inguinal hernia. N Engl J Med. 2004;350(18):1819-27.

26. Genc V, Ensari C, Ergul Z, Kulacoglu H. A very late-onset deep infection after prosthetic inguinal hernia repair. Chirurgia (Bucur). 2010;105(4):555-7.

27. Jeans S, Williams GL, Stephenson BM. Migration after open mesh plug inguinal hernioplasty: a review of the literature. Am Surg. 2007;73(3):207-9.

28. Benedetti M, Albertario S, Niebel T, Bianchi C, Tinozzi FP, Moglia P, et al. Intestinal perforation as a long-term complication of plug and mesh inguinal hernioplasty: case report. Hernia. 2005;9(1):93-5.

29. Bay-Nielson M, Perkins FM, Kehlet H, Danish Hernia Database. Pain and functional impairment 1 year after inguinal herniorrhaphy: a nationwide study. Ann Surg. 2001;233(1):1-7.

30. D'Amore L, Gossetti F, Vermeil V, Negro P. Longterm discomfort after plug and patch hernioplasty. Hernia. 2008;12(4):445-6. 
31. Miller JP, Acar F, Kaimaktchiev VB, Gultekin SH, Burchiel KJ. Pathology of ilioinguinal neuropathy produced by mesh entrapment: case report and literature review. Hernia. 2008;12(2):213-6.

32. Amid PK. Lichtenstein tension-free hernioplasty: its inception, evolution, and principles. Hernia. 2004;8(1):1-7.

33. Mitura K, Romanczuk M. Comparison between two methods of inguinal hernia surgery-Lichtenstein and Desarda. Pol Merkur Lekarski. 2008;24(143):392-5.
34. McRoy LL. Plugoma and the prolene hernia system. J Am Coll Surg. 2010;212(4):424.

Cite this article as: Desarda MP. Desarda repair versus other inguinal hernia repairs: a review of global data of 35578 patients. Int Surg J 2022;9:514-9. 